\title{
Design issues for smart isolation of structures: past and recent research
}

\author{
Ottavia Corbi $^{a}$ *, Alessandro Baratta ${ }^{a}$, Ileana Corbi ${ }^{a}$, Francesca Tropeano $^{a}$, Eugenio Liccardo ${ }^{a}$ \\ ${ }^{a}$ Department of Structures for Engineering and Architecture, University of Naples Federico II, Italy \\ *Corresponding Author: Ottavia Corbi. Email: ottavia.corbi@unina.it
}

\begin{abstract}
The paper focuses on a number of original researches developed by the authors concerned with the development of new design approaches for smart base isolation systems for structures. Base Isolation (BI) systems represent the first kind of control devices applied to civil structures. In the paper, advancement in technology is exploited in this field, allowing to conceive new BI typologies possibly based on the adoption of special smart materials or on the coupling of the basic passive device with additional corrective devices, in such a way to minimize the disadvantages deriving from the simply passive system. Illustrated procedures also embed in the design pattern of base-isolation systems the interaction effects between structure and soil in order to provide the best tuning of the isolation parameters and to get the maximum performance of the devices, finally summarizing a number of original approaches to design under passive, semi-active and hybrid modes.
\end{abstract}

Keywords: Seismic Isolation; damping; stiffness; design

\section{Introduction}

The authors have being involved in the last decades in a number of activities concerning the protection of existing and new structures with regard to ground dynamic excitation, especially with reference to the setup of original formulations and algorithms in the field of structural control [1-12] and to the development of analysis and design tools for refurbishment techniques through composite materials [13-18]. In this research area, and specifically for base isolation systems for civil structures, which is the main focus of the paper, many original formulations have been contributed by the authors, including newly conceived approaches to design, original theoretical setups and development of related analytical tools, generation of original control algorithms, preparation and tune up of ad hoc produced calculation codes for implementing a number of problems and cases, system validation on different structural typologies and execution of wide numerical investigations.

Generally speaking, in the field many researches have been developed from the international scientific community, focused on the mitigation of the dynamic structural response, ranging from the introduction of new control devices, systems, and actuators, the adoption of new strategies and the formulation of the relevant control algorithms to the development of reinforcement techniques, also involving new composite materials, for increasing the dynamic strength of the structure, even in masonry constructions.

A number of studies and applications do refer to the mitigation of structural vibrations through the 000001-1 
adoption of Base Isolation (BI) systems [19-28] in order to shift main frequencies of the structure and prevent magnification effects as much as possible and to dissipate the incoming energy by interrupting foundations' continuity with the underlying soil. Researches by the authors in this field are mainly inspired by the primary objective of making the structure as smart as possible, while setting up new design tools for high-performance isolation systems. In the following some formulations and outcomes developed by the authors are summarized, showing a number of original approaches proposed for improving effectiveness, reliability and economy of the isolation system. They range from more traditional passive modes but with special optimality layout behind the parameters' tuning able to meet upgraded performance, to semi-active and hybrid modes offering further increase of the system effectiveness.

\section{Optimal Isolation Tuning Based on Soil Characteristics}

In some models proposed by the authors for structural isolation, a preliminary stage is concerned with the design of the isolation device itself accounting for the characteristics of the ground filter at the site. In these cases the isolation device is designed according to the passive mode, starting from the concept that the performance of base-isolation devices in mitigating inertia forces due to intense earthquakes strongly depends on the proper calibration of the isolation devices own frequency, that should take into account both the dynamical characteristics of the superstructure and the frequency content of the expected disturbance.

One should emphasize that passive base-isolation systems still represent, at present, one of the most efficient and economic passive devices able to dissipate most of the disturbance energy without damage to the protected super-structure. Under this perspective, some approaches are summarized aimed at taking into account, at the design stage, the interaction effects between the structure itself and the soil characterizing the site, since this behaves like a filter as regards to the incoming seismic excitation, mainly affecting its frequency composition and, definitively, its overall dynamic character.

This type of approach is then mainly aimed at incorporating in the control algorithm an optimization pattern even concerned with the specific properties of the soil and, to this extent, an ad hoc procedures are developed based on analysis tools formulated in the frequency domain, for subsequent steps involving the optimization stage.

\subsection{Frequency Analysis}

In these models, because of the random character of the seismic excitation, statistical properties are referred to, through the cross spectral densities of the response $\Phi_{\mathrm{u}}(\omega)$ and of the excitation $\Phi_{\mathrm{f}}(\omega)$, being $\mathbf{u}(\mathrm{t})$ and $\mathbf{f}(\mathrm{t})$ the displacement and excitation vectors for the $\mathrm{n}$-dof shear frame structures.

The following relationships are inferred

$\boldsymbol{\Phi}_{u}(\omega)=\mathbf{H}(\omega) \boldsymbol{\Phi}_{f}(\omega) \overline{\mathbf{H}}^{T}(\omega)$

where the conjugate $\left(^{-}\right)$and transpose operators $(\cdot)^{\mathrm{T}}$ are dealt with, upon introduction of the frequency response functions' matrix $\mathbf{H}(\omega)$

$$
\mathbf{H}(\omega)=[\mathbf{A}(\omega)+i \mathbf{B}(\omega)]^{-1}=\frac{1}{\Delta}\left[\mathbf{A}^{*}(\omega)+\mathbf{B}^{*}(\omega)\right]
$$

with

$$
\begin{aligned}
& \Delta=[|\mathbf{A}(\omega)|-|\mathbf{B}(\omega)|]+i\left[\mathbf{B}(\omega) \cdot \mathbf{A}^{*}(\omega)\right] \\
& \mathbf{A}(\omega)=\mathbf{K}-\omega^{2} \mathbf{M}, \quad \mathbf{B}(\omega)=\omega \mathbf{C}, \quad \mathbf{A}^{*}(\omega)=|\mathbf{A}(\omega)| \mathbf{A}^{-1}(\omega), \quad \mathbf{B}^{*}(\omega)=|\mathbf{B}(\omega)| \mathbf{B}^{-1}(\omega)
\end{aligned}
$$

where (.) refers to scalar product, $\mathbf{M}, \mathbf{C}$ and $\mathbf{K}$ denote the mass, damping and stiffness matrices, and the real and imaginary parts of $\mathbf{H}(\omega)$ are to be handled. 
In case of a sdof isolated shear frame, one may infer through a series of algebraic operations the matrix of drifts' cross spectral densities $\Phi_{x}(\omega)$, whose elements are finally expressed in the form of functions of the ground acceleration spectral density $\Phi_{\ddot{u}_{\mathrm{g}}}(\omega)$, in turn related with the matrix of the storey force vector $\Phi_{\mathrm{f}}(\omega)$, according to the following explicit equations

$$
\begin{aligned}
& \Phi_{x_{i s} x_{i s}}(\omega)=\left[a_{4} \omega^{4}+a_{2} \omega^{2}+a_{0}\right] \cdot \frac{\Phi_{\ddot{u}_{g}}(\omega)}{|\Delta|^{2}}, \\
& \Phi_{x_{i s} x_{s t r}}(\omega)=\Phi_{x_{s t r} x_{i s}}(\omega)=\left[b_{2} \omega^{2}+b_{0}\right] \cdot \frac{\Phi_{\ddot{u}_{g}}(\omega)}{|\Delta|^{2}} \\
& \Phi_{x_{s t r} x_{s t r}}(\omega)=\left[d_{2} \omega^{2}+d_{0}\right] \cdot \frac{\Phi_{\ddot{u}_{g}}(\omega)}{|\Delta|^{2}}
\end{aligned}
$$

Where the isolation and structure storeys' properties are marked by the indexes $(\cdot)_{\text {is }}$ and $(\cdot)_{\text {str }}$ respectively, and with

$$
\begin{aligned}
& \left\{\begin{array}{l}
a_{0}=m_{i s}^{2} k_{s t r}^{2}+2 m_{i s} m_{s t r} k_{s t r}^{2}+m_{s t r}^{2} k_{s t r}^{2} \\
a_{2}=m_{i s}^{2} c_{s t r}^{2}-2 m_{i s}^{2} m_{s t r} k_{s t r}+2 m_{i s} m_{s t r} c_{s t r}^{2}-2 m_{i s} m_{s t r}^{2} k_{s t r}+m_{s t r}^{2} c_{s t r}^{2} \\
a_{4}=m_{i s}^{2} m_{s t r}^{2}
\end{array}\right. \\
& \left\{\begin{array}{l}
b_{0}=m_{i s} k_{i s} m_{s t r} k_{s t r}+k_{i s} m_{s t r}^{2} k_{s t r} \\
b_{1}=m_{i s} k_{i s} m_{s t r} c_{s t r}-m_{i s} c_{i s} m_{s t r} k_{s t r}-c_{1} m_{s t r}^{2} k_{s t r}+k_{1} m_{s t r}^{2} c_{s t r} \\
b_{2}=-m_{i s} k_{i s} m_{s t r}^{2}+m_{i s} c_{i s} m_{s t r} c_{s t r}+c_{i s} m_{s t r}^{2} c_{s t r} \\
b_{3}=m_{i s} c_{i s} m_{s t r}^{2}
\end{array}\right. \\
& \left\{\begin{array}{l}
d_{0}=k_{i s}^{2} m_{s t r}^{2} \\
d_{2}=c_{i s}^{2} m_{s t r}^{2}
\end{array}\right.
\end{aligned}
$$

Where $\mathrm{m}, \mathrm{c}, \mathrm{k}$ denote the mass damping and stiffness.

The ground acceleration spectral density $\Phi_{\text {i. }_{\mathrm{g}}}(\omega)$ may be expressed as a function of the soil characteristics $\xi$ and $\eta$, representing the soil damping and own frequency respectively, through the following filter equation

$$
\Phi_{\ddot{u}_{g}}(\omega)=\frac{4 \xi^{2} \eta^{2} \omega^{2}+\eta^{4}}{\left(\omega^{2}-\theta_{1}\right)\left(\omega^{2}-\theta_{2}\right)}, \theta_{1}=-\eta^{2}(\kappa+\xi \sqrt{2 \kappa}), \quad \theta_{2}=-\eta^{2}(\kappa-\xi \sqrt{2 \kappa}), \quad \kappa=2 \xi^{2}+1
$$

\subsection{Design Stage}

Since under this overall strategy the isolation system is still conceived in its passive mode, the primary objective of the tuning design stage is identified in the optimization of its properties with regards to both the soil and the structure mechanical characteristics. This approach is able to guarantee a major effectiveness of the system because it takes into account the soil that largely affects the frequency composition of the structural response and, definitively, its overall dynamic character, behaving like a kind of filter.

For a n-dof shear-type frame (including the first degree of freedom relevant to the isolation storey, referred to by the index (.)is), this objective can be pursued by imposing that the isolator minimizes the 
energy introduced in the structure $\mathcal{E}_{s t r}\left(m_{i s}, c_{i s}, k_{i s} \mid \eta, \xi\right)$ by the dynamic excitation, while allowing a bounded energy absorption $\mathcal{E}_{i s}\left(m_{i s}, c_{i s}, k_{i s} \mid \eta, \xi\right)$ in the isolator, to be kept lower than a prefixed threshold $\overline{\mathcal{E}}_{i s}$.

These types of approaches may then lead to formulations for the control algorithm mainly concerned with the solution of a suitably defined constrained optimum problem where some response and excitation energy measures are involved and requested to be solved.

One possible set up of the problem is the following

$$
\begin{cases}\text { Find } & \min _{m_{1}, c_{1}, k_{1}} \mathcal{E}_{s t r}\left(m_{i s}, c_{i s}, k_{i s} \mid \eta, \xi\right) \\ \text { Sub } & \mathcal{E}_{i s}\left(m_{i s}, c_{i s}, k_{i s} \mid \eta, \xi\right) \leq \overline{\mathcal{E}}_{i s}\end{cases}
$$

Problems of the type of Eq.(7) are aimed at tuning of the isolator parameters that are able minimize the energy absorbed by the structure while containing the energy introduced at the isolation level. Possibly additional constraints may be accounted for, for example with reference to minimum bounds on the isolation mass.

The evaluation of the mentioned energies as functions of the varying isolator characteristics and of the soil properties can be related to the storey energies $\mathcal{E}_{k}\left(m_{i s}, c_{i s}, k_{i s} \mid \eta, \xi\right)$ with $\mathrm{k}=1,2 \ldots \mathrm{n}$, referred to the integrals of the relevant auto-spectral density terms $\Phi_{\mathrm{x}_{\mathrm{k}} \mathrm{x}_{\mathrm{k}}}(\omega)$ (with xk the inter-storey drift of the k-th floor), as follows

$$
\begin{aligned}
& \mathcal{E}_{k}\left(m_{i s}, c_{i s}, k_{i s} \mid \eta, \xi\right)=\int_{-\infty}^{+\infty} \Phi_{x_{k} x_{k}}(\omega) d \omega, \\
& \mathcal{E}_{i s}\left(m_{i s}, c_{i s}, k_{i s} \mid \eta, \xi\right)=\mathcal{E}_{1}\left(m_{i s}, c_{i s}, k_{i s} \mid \eta, \xi\right), \\
& \mathcal{E}_{s t r}\left(m_{i s}, c_{i s}, k_{i s} \mid \eta, \xi\right)=\sum_{k=2}^{n} \mathcal{E}_{k}\left(m_{i s}, c_{i s}, k_{i s} \mid \eta, \xi\right)
\end{aligned}
$$

The dependence of the auto-spectral density terms $\Phi_{\mathrm{x}_{\mathrm{k}} \mathrm{x}_{\mathrm{k}}}(\omega)$ on the ground acceleration spectral density $\Phi_{\mathrm{u}_{\mathrm{g}}}(\omega)$ allows to set up the above mentioned design procedure for choosing the optimal isolation parameters with respect to the soil mechanical properties at the site, expressed through its parameters and.

\subsection{Numerical Investigation}

These types of approaches have been broadly validated. Numerical analyses have been conducted on suitably defined indexes able to synthesize the convenience in adopting the isolation depending on the site characteristics, with respect to the case of no isolation. Data show that in the cases when the soil is already very soft or poorly stiff with comparison to the structure, the isolator is not useful.

In Fig.1 some synthetic diagrams are represented, after executing the optimization process on an isolated sdof shear frame. The diagrams report the maximum response values attained by the isolation device and by the superstructure under the excitation, for varying isolator parameters $\omega_{1}$ and $\zeta_{1}$.

\section{Smart Isolation Systems through Semi-active Devices}

Some smart technologies exploiting the particular properties of special materials such as Shape Memory Alloys (SMAs) have been investigated by the authors, even with reference to the realization of BI devices.

\subsection{Semi-active Isolation}


In the following one synthetically reports some results obtained through design of semi-active SMA isolation devices for mdof shear frame models (Fig.2.a) exhibiting an elastic perfectly plastic behaviour, under the action of a seismic-type dynamic excitation. (Fig.2.b), in order to provide the main structure with a dissipation device able to attenuate the effects induced by the incoming dynamic excitation also in terms of recovering of residual plastic deformations; obviously, the exploitation of the pseudo-elastic character of the SMA members requires a suitable tuning of the alloy parameters on the basis of the structure mechanical and geometrical characteristics [3-5].

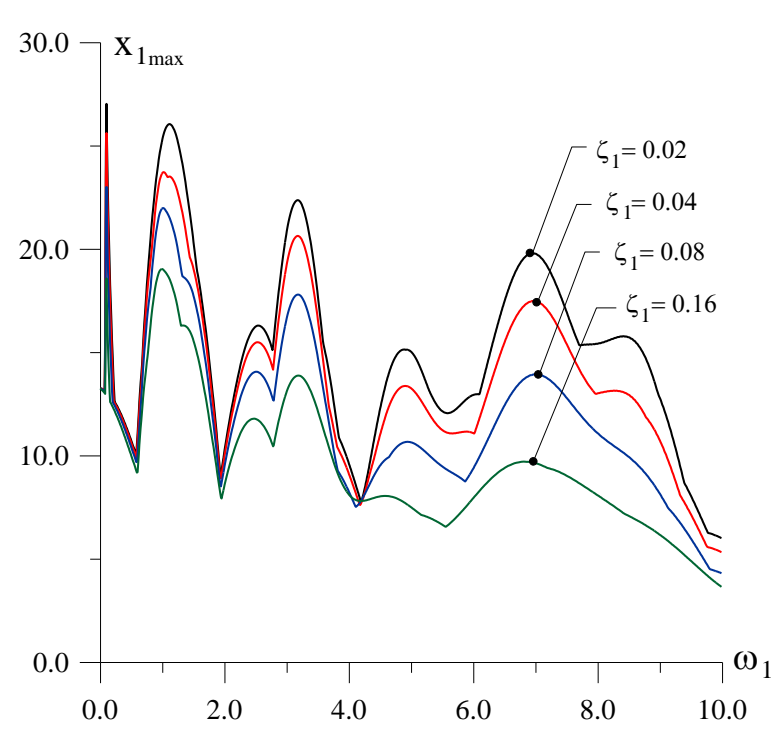

(a) Isolation

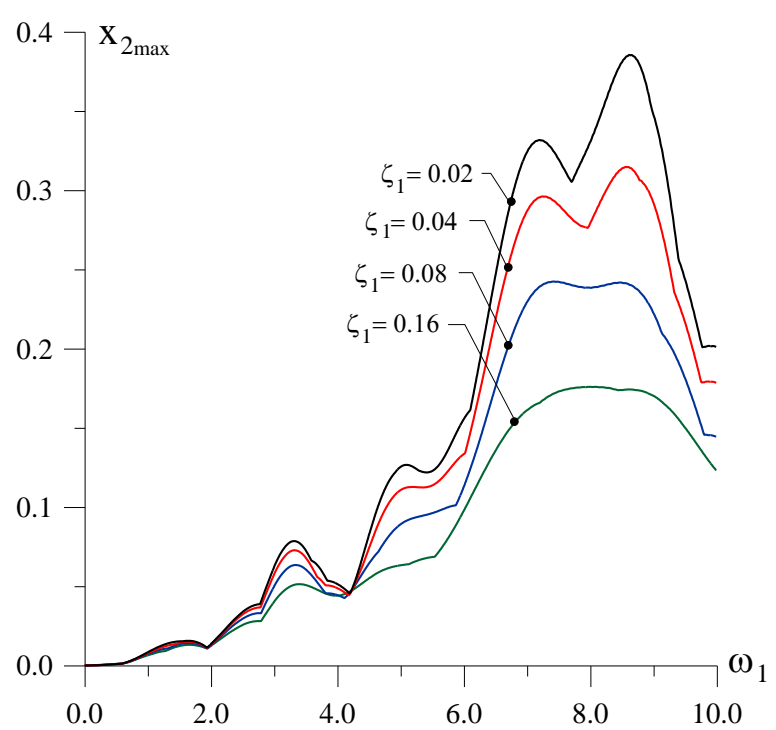

(b) Structure

Fig. 1. Curves of the maximum drifts attained during the motion by varying the isolator parameters $\omega_{1}$ and $\zeta_{1}$

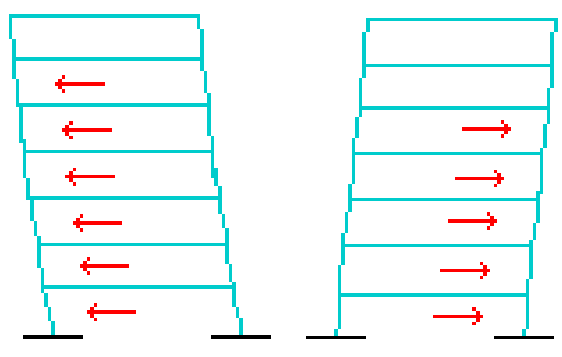

(a) without SMA isolation

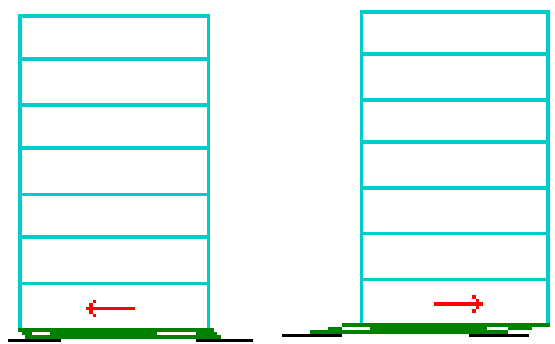

(b) with SMA isolation.

Fig. 2. Sketches produced from the calculus code of the shear frame model during the motion:

\subsection{Numerical Analyses}

As an example of executed numerical investigations, let refer to a shear-frame model with 7degrees of freedom. The model is assumed to exhibit an elastic-perfectly plastic behaviour and its characteristics, in terms of storey mass mi, stiffness $\mathrm{k}_{\mathrm{i}}$, damping capacity $\mathrm{c}_{\mathrm{i}}$ and yield shear limits $T_{o i}^{\prime}, T_{o i}^{\prime \prime}$ (positive in the rightward direction and negative in the leftward direction) are given in Table 1.

One reports some of the results relevant to the case of a base acceleration varying according to the rule $\ddot{u}_{g}(t)=0.5 \cdot g \cdot\left[\sin \left(\omega_{f 1} t\right)+\sin \left(\omega_{f 2} t\right)\right] \cdot t \cdot e^{-\lambda t}$, with $g$ the gravity acceleration, $\omega_{\mathrm{f} 1}=10 \mathrm{rad} \cdot \mathrm{sec}^{-1}$, $\omega_{\mathrm{f} 2}=30 \mathrm{rad} \cdot \mathrm{sec}^{-1}, \lambda=5 / \mathrm{T}$ and overall duration $\mathrm{T}=5$ secs. The sketches of the structure motion (as produced by the ad hoc created calculus code implementing the problem) with and without SMA provision under the given forcing function in the two loading directions are reported in Fig.2: arrows indicate the directions of plastic excursions when they occur. Most of the dynamic excitation energy is 
dissipated by the isolator which prevents the superstructure from entering the plastic phase. In the numerical investigation one evaluates the quantities relevant to the maximum value of absolute interstorey plastic drift $\left[\Delta u_{p}(t)\right]_{\max }=\max _{j=1 \ldots .7}\left|\Delta u_{p j}(t)\right|$ in the structure or in the super-structure in case of isolation. One immediately observes a strong reduction of the structural response, since in case of SMA isolation maximum storey drifts are strongly reduced and plastic excursions are rarely encountered, differently from the case when no semi-active isolation is present and almost all floors experience strong plastic response, as shown by the presence of arrows.

Table 1: Model characteristics.

\begin{tabular}{cccccc}
\hline $\mathrm{i}^{\text {th }}$ level & $\begin{array}{c}\mathrm{m}_{\mathrm{i}} \\
\left(\mathrm{kg} \cdot \mathrm{sec}^{2} / \mathrm{cm}\right)\end{array}$ & $\begin{array}{c}\mathrm{c}_{\mathrm{i}} \\
(\mathrm{kg} \cdot \mathrm{sec} / \mathrm{cm})\end{array}$ & $\begin{array}{c}\mathrm{k}_{\mathrm{i}} \\
(\mathrm{kg} / \mathrm{cm})\end{array}$ & $\begin{array}{c}\mathrm{T}^{\prime}{ }_{\mathrm{oi}} \\
(\mathrm{kg})\end{array}$ & $\begin{array}{c}\mathrm{T}^{\prime \prime}{ }_{\mathrm{oi}} \\
(\mathrm{kg})\end{array}$ \\
\hline 1 & 20 & 200.000 & 200000 & 22759.20 & -22759.20 \\
2 & 16 & 185.714 & 185714 & 21675.43 & -21675.43 \\
3 & 16 & 171.439 & 171439 & 20591.66 & -20591.66 \\
4 & 16 & 157.142 & 157142 & 19507.89 & -19507.89 \\
5 & 16 & 142.857 & 142857 & 18424.12 & -18424.12 \\
6 & 16 & 128.571 & 128571 & 17340.34 & -17340.34 \\
7 & 16 & 114.286 & 114286 & 16256.57 & -16256.57 \\
\hline
\end{tabular}

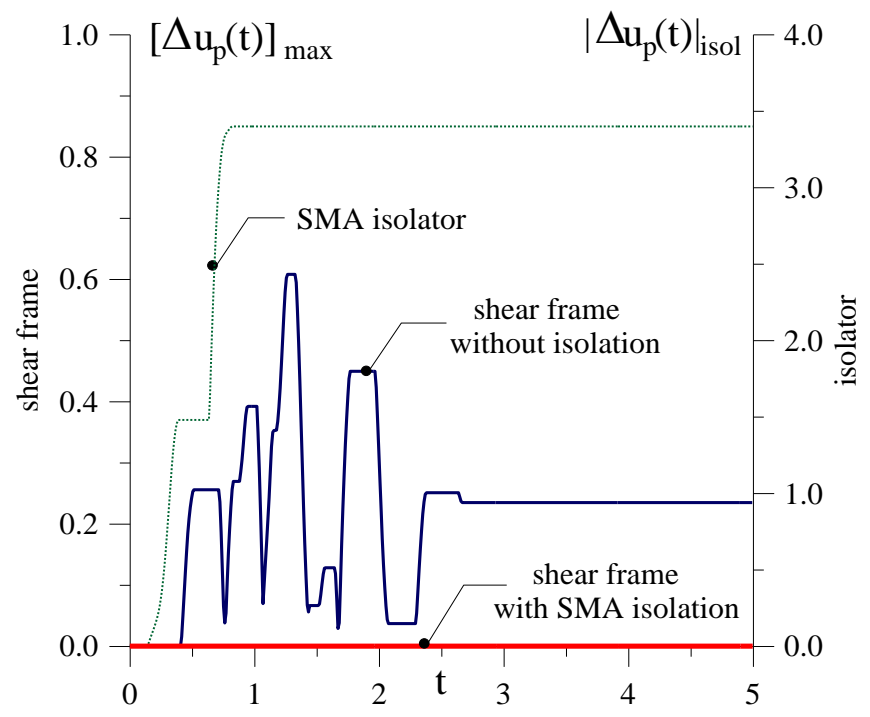

Fig. 3. Maximum plastic drift in the shear frame and isolator plastic drift.

More specifically in Fig.3 one can observe the comparison of the maximum absolute inter-storey plastic drift in the un-isolated shear frame with the values attained in case of SMA isolation. One can still notice that practically no plastic excursion occur in case of SMA isolation and that a drastic reduction of the structural response occurs.

Furthermore, the inter-storey drifts $\Delta u_{1}(t), \Delta u_{7}(t)$ at the $1^{\text {st }}$ and $7^{\text {th }}$ levels of the structure are also monitored. The evaluation of analogous quantities at the isolation level is also accounted for, i.e. the absolute plastic drift $\left|\Delta u_{p}(t)\right|_{\text {isol }}$ and the total drift $\Delta u_{i s o l}(t)$. One can notice that no plastic excursion occurs in the latter case. The inter-storey drifts at the $1^{\text {st }}$ and $7^{\text {th }}$ levels for structure equipped or not with SMA isolation device are reported along with the isolator displacement in Fig.4. A wide response attenuation can be observed in case of adoption of the SMA provision with a practically zero final residual deformation. This circumstance is quite clear from Fig.4.a, where one can notice 
significant residual values in the system response after the end of the motion, whilst the frame is completely recentered to the original position when introducing SMA isolation.

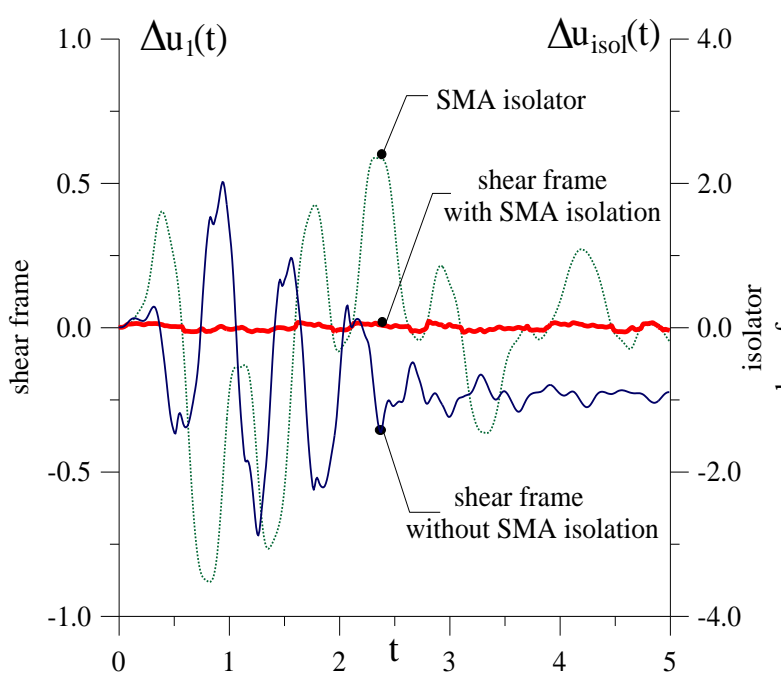

(a) the $1^{\text {st }}$ floor

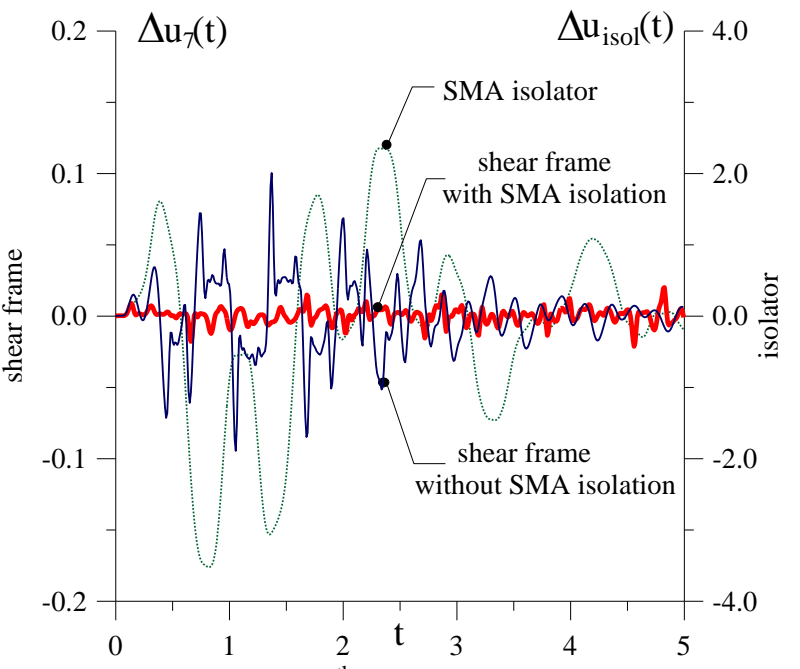

(b) the $7^{\text {th }}$ floor.

Fig. 4. Drift in the shear frame with and without SMA isolation

\section{Hybrid Isolation Devices}

Isolation devices designed in passive mode may result not completely effective under unexpected conditions. As shown in Sect.2, from the analysis of the optimization results one can figure out some general considerations about the effectiveness of a passive base-isolation device. One can observe that in cases when the soil is already very soft or poorly stiff with comparison to the structure, the isolation of the building is not really useful. This intrinsic limitation to the effectiveness of the passive baseisolator, even if optimally designed taking into account also the characters of the soil, cannot be overcome.

In the following one summarizes some strategy developed by the authors where some combined control approaches are proposed able to couple active vibration devices and passive isolation devices, thus realizing hybrid control systems.

Actually, some significant improvement of the performance of the base-isolation designed in Sect. 2 in function of the structure and soil characteristics may be obtained when turning the passive isolation into an active one, i.e. when adopting an additional device able to infer additional forces counteracting the incoming excitation, whose control parameters should be carefully tuned according to some optimality criterion.

\subsection{The Control Algorithm}

In this section one refers to models developed by the authors where the performance of the control isolation system is improved through combination with some additional device accounting for ranges where the main system is not fully effective, to be activated only in case it turns helpful.

The objective of the strategy consists of increasing the reliability of the overall control system in terms of attenuation of the dynamic response of the structure under the incoming excitation.

After denoting by $(\cdot)_{\mathrm{BI}}$ quantities relevant to the isolation storey, one selects a control action applied at the isolation level of the type $w_{B I}(\omega, t)=p(\omega) y_{B I}(t)+q(\omega) \dot{y}_{B I}(t)$ consisting of a proportional/derivative rule through the control coefficients $\mathrm{p}(\omega)$ and $\mathrm{q}(\omega)$. 
The controlled system's gain matrix $\mathrm{H}[\omega \mid p(\omega), q(\omega)]$ between the structure displacement and the base acceleration vector is then inferred in the form

$\mathrm{H} \quad[\omega \mid p(\omega), q(\omega)]=-\left\{\left[\mathbf{K}+p(\omega) \mathbf{P}-\omega^{2} \mathbf{M}\right]+j \omega[\mathbf{C}+q(\omega) \mathbf{Q}]\right\}^{-1}\left(\frac{\mathbf{K}+j \omega \mathbf{C}}{\omega^{2}}\right)$

where $\mathbf{P}$ and $\mathbf{Q}$ denote the matrixes governing the distribution of the control action and the dependence on the response variables, as well as the gain of the isolation device

$\mathrm{H}_{B I}^{*}[\omega \mid p(\omega), q(\omega)]=\sum_{j} \mathrm{H}_{B I, j}[\omega \mid p(\omega), q(\omega)]$

In order to select the most effective control action to be applied, the strategy may consist of optimizing the process through an approach accounting for recorded data from the structure under the ground motion till the moment of application of the control action and adopting a control force such that

$[\mathbf{w}(\tau \mid \theta)]_{\theta=\tau}=\mathbf{w}(\tau) \quad \forall \tau \in[-\theta, \theta]$

The control force to be applied at the instant t may be obtained by instantaneously adding to the current control force expression, based on the Fourier transform of the data recorded up to the current instant, the updated value of the error that should be suitably calculated.

After some developments, the expression of the instantaneous control action depending on the online parameters can be found in a form of the type

$\mathbf{w}(t)=\mathbf{w}(t \mid \theta)-\frac{2}{\pi} \int_{0}^{t} \mathbf{f}_{g}(\tau) \Pi(t \mid \tau) d \tau-\frac{2}{\pi} \int_{0}^{t} \mathbf{f}_{g}(\tau) \Psi(t \mid \tau) d \tau$

with the two functions $\Pi(\mathrm{t} \mid \tau)$ and $\Psi(\mathrm{t} \mid \tau)$ depending on the feedback convolution.

The optimization procedure for the final search of the optimal coefficients and the control algorithm is then set by solving the optimum problem as follows, where the maximum control action

$\mathrm{W} \quad[\omega \mid p(\omega), q(\omega)]=\operatorname{Max}_{\mathrm{p}(\omega), \mathrm{q}(\omega)} \mathrm{W}[\omega \mid p(\omega), q(\omega)]$

is minimized.

The maximum controlled shear

$\mathrm{S}[\omega \mid p(\omega), q(\omega)]=\underset{p(\omega), q(\omega)}{\operatorname{Max}} \mathbf{s}[\omega \mid p(\omega), q(\omega)]$

is kept bounded under a prefixed threshold of the uncontrolled response through an attenuation function $\alpha(\omega)$.

$\begin{cases}\text { Search } & \underset{p(\omega), q(\omega)}{\operatorname{Min} W} \quad[\omega \mid p(\omega), q(\omega)] \\ \text { Sub } & \mathrm{S}[\omega \mid p(\omega), q(\omega)] \leq \alpha(\omega) \mathrm{S}[\omega \mid 0,0]\end{cases}$

\subsection{Numerical Application of the Procedure on Mdof Shear Frames}

Results from the implementation of the illustrated control approach are synthetically shown with reference to a base-isolated shear frame with four storeys (besides the isolation device) with storey masses, stiffness and damping given as follows

$\mathrm{m}_{\mathrm{i}}=\mathrm{m}_{\mathrm{BI}}=6 \times 10^{4} \mathrm{~kg}, \mathrm{k}_{\mathrm{i}}=3 \times 10^{8} \mathrm{~kg} / \mathrm{m}, \mathrm{k}_{\mathrm{BI}}=0.05 \mathrm{k}_{\mathrm{i}}, \zeta_{\mathrm{i}}=2 \%, \zeta_{\mathrm{BI}}=1 \%, \mathrm{i}=1, \ldots, 4$

(16)

The numerical investigation is performed with reference to a ground action simulating a white noise base acceleration with zero mean and unitary variance, scaled to a peak acceleration of $0.4 \mathrm{~g}$. Simple derivative feedback is considered and a response reduction percentage of $\gamma=1 / 60$ is adopted. 
Results are quite encouraging in terms of reduction of the structural response.

Numerical simulations show that the isolator drift is consistently reduced (Fig.5), as well as the inter-storey displacements of the super-structure (some of them are reported in Fig.6).

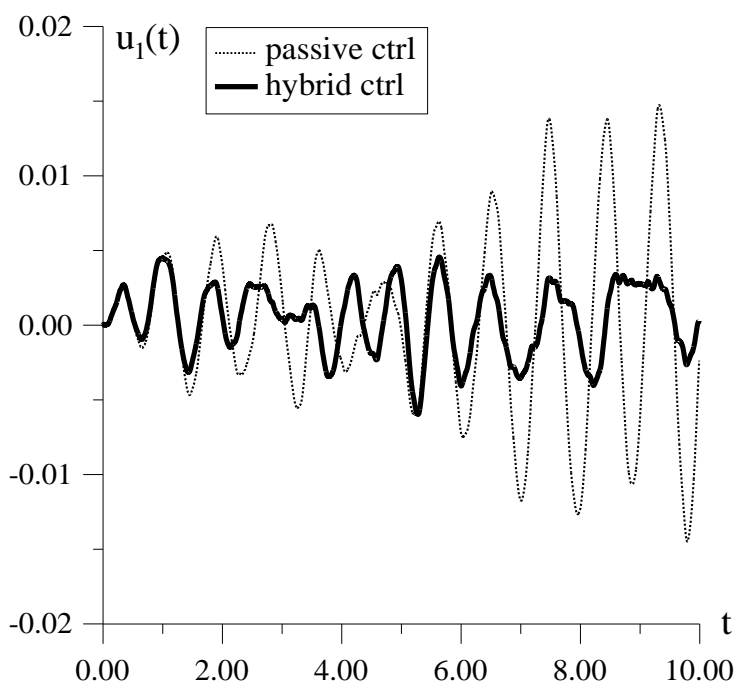

Fig. 5. Isolation drift u1(t).

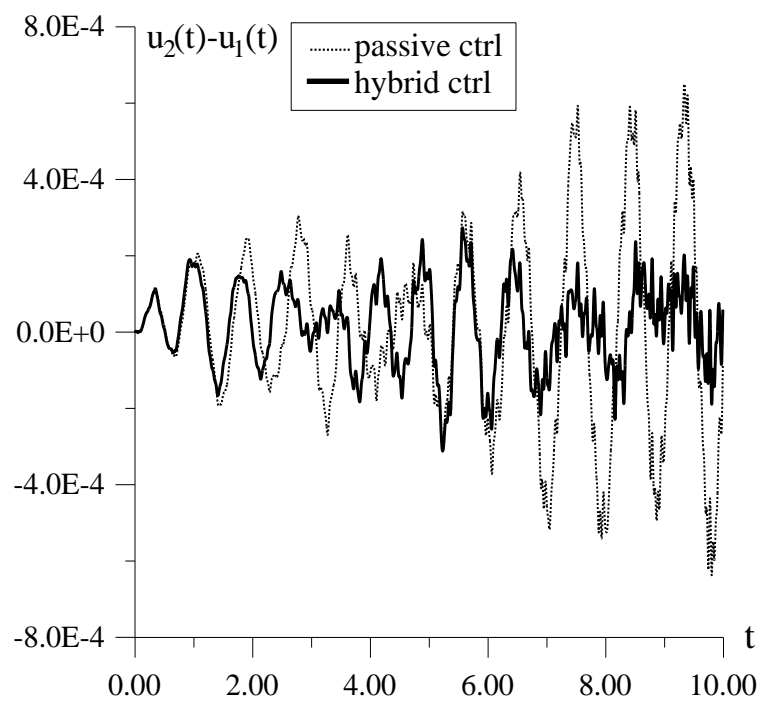

(a) 2nd-1st floor drift

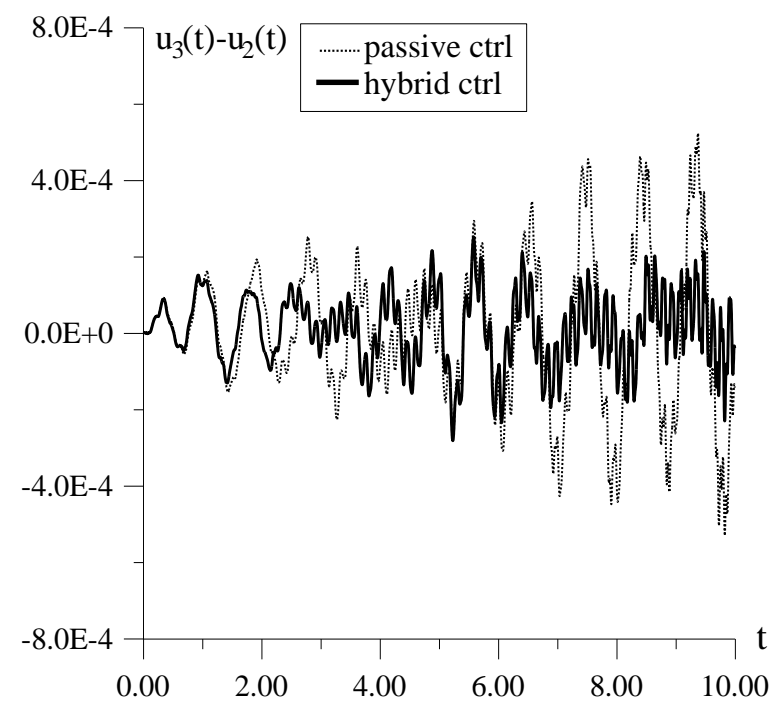

(b) 3rd-2nd floor drift

Fig. 6. Hybrid B.I. tuned on the soil and structure properties. Inter-storey drifts of the super-structure:

As one can observe from Fig.5, the differential displacements of the main structure at the isolation floor are compared, attained in the two cases when the control action of the base isolation system is not corrected (dashed line), and in case it is enhanced through the further control action, selected according to the above shown procedure (continuous line).

One may appreciate a significant further mitigation with respect to the passive mode achieved through the proposed approach, able to further improve the performance of the control system.

Similar attenuation may be observed at higher floors.

Actually, the numerical investigation shows a very good performance of the final control hybrid system with comparison to traditional devices, since besides the benefits related to the further reduction of the structural response, the procedure is optimized for requiring a very low energy amount in order to be effective: actually for the adoption attenuation coefficient $\gamma=1 / 60$ the maximum value of the 
control action is equal approximately to $1 / 30$ of the maximum value of the forcing function. Moreover, a certain degree of flexibility is kept in order to choose the preferred level of attenuation according to the requested economy of the operating system.

\section{Conclusions}

In the paper one focuses on some approaches developed by the authors for designing BI isolation devices with improved performance. Either passive or semi-active and hybrid procedures for the design of the isolation systems are shown.

As concerns the passive mode, the illustrated approach is aimed at optimally calibrating the mechanical properties of a seismic isolation device for attenuating structural dynamic effects on the basis of the knowledge of the mechanical properties of the superstructure and of the soil properties.

Since in designing effective structural isolation devices a fundamental role is played by the spectral dominant characters of the expected shaking, which, in turn, are deeply related to the macro-properties of the subsoil at the specific site, procedures are summarized for properly designing the isolation device based on the soil Kanai-Tajimi spectrum data, demonstrating high performance and reliability within some ranges of soil properties.

Further possibilities investigated by the authors for realizing effective isolation systems are offered by the exploitation of properties of smart materials. One specifically refers to Shape Memory Alloys, presenting some semi-active actuators able to take advantages of the special behaviour of the alloys. Numerical investigations are summarized strongly confirming these materials as potential candidates for structural applications because of their high dissipative and re-centring skills.

In the last section of the paper, one synthetically reports approaches designed under hybrid mode.

Actually, isolation devices, as passive provisions, may turn to be inadequate or not properly effective in given situations, like in case of soft soils. In this case, also for already isolated constructions, some intervention might be required that implies to re-conceive the whole system in order to achieve more satisfactory results in terms of response mitigation under seismic motion. Under these perspectives some strategies are illustrated setting up procedures for designing some corrective actions, to be exerted only if needed. These hybrid systems are shown to be able to prevent possible dynamic magnification induced by the isolation itself, and to improve the overall system performance.

\section{Acknowledgement}

The present research has been supported by the Dept of Civil Protection of the Italian Government through the ReLuis Pool.

\section{Conflicts of Interest}

The authors declare no conflict of interest.

\section{References}

[1] Baratta A, Corbi I, Corbi O, Mastorakis N. Strategies for the protection from structural failures under seismic events. Int J Mech 2015; 9: 69-76.

[2] Baratta A, Corbi I, Corbi O. Algorithm design of a hybrid system embedding influence of soil for dynamic vibration control. Soil Dyn Earthq Eng 2015; 74: 79-88. https://doi.org/10.1016/j.soildyn.2015.03.011.

[3] Corbi I, Corbi O. Macro-mechanical modelling of pseudo-elasticity in shape memory alloys for structural applications. Acta Mech 2016; 227(8): 2171-2179. https://doi.org/10.1007/s00707-016-1624-3.

[4] Corbi I, Corbi O, Li H. Convolutive PD controller for hybrid improvement of dynamic structural systems. Soil Dyn Earthq Eng 2020; 137: 106255. https://doi.org/10.1016/j.soildyn.2020.106255.

[5] Corbi I, Corbi O, Li H. A coupled control strategy for the mitigation of structural vibrations. Ing Sismicaital 2019; 36(3): 107-115.

[6] Corbi I, Corbi O, Li H. A constrained energy minimum approach to modal dynamic control of vibrations in 
ancient nonlinear structures. Int J Struct Stab Dy 2019; 19(06): 1950054. https://doi-org.mxg.80599.net/10.1 142/S0219455419500548.

[7] Corbi I, Corbi O, Li H. Optimum design of dynamic modal control algorithm using non-linear structural mathematical modelling. Soil Dyn Earthq Eng 2018; 114: 548-554. https://doi.org/10.1016/j.soildyn.2018.0 7.033 .

[8] Corbi I, Corbi O. Development and implementation of a control system for the dynamic mitigation of 3-D masonry structures with feedback on the drifts in the horizontal plane. Struct Control Health Monit 2018; 25(8): e2176. https://doi-org.xjpgl.80599.net/10.1002/stc.2176.

[9] Corbi I, Rakicevic ZT. Shaking table testing for structural analysis. Int J Mech 2013; 7(4): 459-466.

[10] Corbi O, de Barros RC. Seismic protection of civil buildings by visco-elastic magneto-rheological fluids. Int J Mech 2013; 7(4): 518-525.

[11] Corbi O, Zaghw AH. Properties and design of dissipative viscorecentring SMA members for civil structures. Int J Mech 2013; 7(3): 285-292.

[12] Corbi O, Zaghw AH, Elattar A, Saleh A. Preservation provisions for the environmental protection of egyptian monuments subject to structural vibrations. Int J Mech 2013; 7(3): 172-179.

[13] Baratta A, Corbi I. FRP composites retrofitting for protection of monumental and ancient constructions. The Open Construction and Building Technology Journal 2012; 6(1). https://doi.org/10.2174/18748368012060 10361.

[14] Baratta A, Corbi O. An approach to the positioning of FRP provisions in vaulted masonry structures. Compos Part B Eng 2013; 53: 334-341. https://doi.org/10.1016/j.compositesb.2013.04.043.

[15] Corbi I. FRP reinforcement of masonry panels by means of C-fiber strips. Compos Part B Eng 2013; 47: 348-356. https://doi.org/10.1016/j.compositesb.2012.11.005.

[16] Baratta A, Corbi I. Topology optimization for reinforcement of no-tension structures. Acta Mech 2014; 225 (3): 663-678. https://doi.org/10.1007/s00707-013-0987-y.

[17] Baratta A, Corbi O. Closed-form solutions for FRP strengthening of masonry vaults. Comput Struct 2015; 147: 244-249. https://doi.org/10.1016/j.compstruc.2014.09.007.

[18] Corbi I, Corbi O. Analysis of bi-dimensional solids with internal unilateral constraint coupled to structural elements with different degree of connection. Acta Mech 2017; 228(2): 607-616. https://doi.org/10.1007/s0 0707-016-1723-1.

[19] Kelly JM. Aseismic base isolation: review and bibliography. Soil Dyn Earthq Eng 1986; 5(4): 202-216. https://doi.org/10.1016/0267-7261(86)90006-0.

[20] Kelly JM. Base isolation: linear theory and design. Earthq Spectra 1990; 6(2): 223-244. https://doiorg.wlu.80599.net/10.1193/1.1585566.

[21] Buckle IG, Mayes RL. Seismic isolation: history, application, and performance - a world view. Earthq Spectra 1990; 6(2): 161-201. https://doi-org.wlu.80599.net/10.1193/1.1585564.

[22] Jangid RS, Datta, TK. Seismic behaviour of base-isolated building - a state of the art review. P I Civil EngStr B 1995; 110(2): 186-203. https://doi.org/10.1680/istbu.1995.27599.

[23] Naeim F, Kelly JM. Design of seismic isolated structures: from theory to practice. John Wiley and Sons: Hoboken 1999.

[24] Pranesh M, Sinha R. VFPI: an isolation device for aseismic design. Earthq Eng Struct D 2000; 29(5): 603627. https://doi.org/10.1002/(SICI)1096-9845(200005)29:53.0.CO;2-W.

[25] Soong TT. Active structural control: Theory and practice. Longman, England and Wiley 2000.

[26] Constantinou MC, Whittaker AS, Kalpakidis Y, Fenz DM, Warn GP. Performance of seismic isolation hardware under service and seismic loading; Technical Report MCEER-07-0012; Multidisciplinary Center for Earthquake Engineering Research, State University of New York at Buffalo: Buffalo, NY, USA 2008.

[27] Taylor A, Aiken I. What's Happened to Seismic Isolation of Buildings in the U.S.? Struct 2011; 10-13.

[28] Oh SH, Song SH, Lee SH, Kim HJ. Seismic response of base isolating systems with U-shaped hysteretic dampers. Int J Steel Struct 2012; 12(2): 285-298. https://doi.org/10.1007/s13296-012-2011-0. 